\title{
Stability Behavior of Plate Girders with Laterally
}

\section{Unbraced Ends}

\author{
Yiyun Zhu and Jing Jiang \\ Department of Civil Engineering, Shanghai Jiao Tong University, Shanghai 200240, China
}

\begin{abstract}
Stability tests of three plate girders laterally unbraced on both ends, which were scale models of real plate girders in heavy plants for tower-type boilers, are presented and investigated. The applicability of code provisions in ANSI/AISC 360-10 about such members is discussed. A nonlinear finite element analysis was carried out, considering the combined effects of plasticity, residual stress and geometrical imperfections, to simulate the stability behavior of the specimens. The reliability of the numerical model was validated by comparisons with experimental results. The results show that stability behavior of plate girders with laterally unbraced ends is widely different from that of typical simply supported thin-walled beams. The structural response is also sensitive to initial geometrical imperfections of this objects. The model is used to improve the mechanical design of transverse stiffeners over the supports. The positive effect and offsetting influence of imperfections of thicker and additional transverse stiffeners on overall stability behavior are highlighted. A few suggestions for design process are also given.
\end{abstract}

Key words: Plate girder, lateral-torsional buckling, boundary condition, numerical modeling, ANSI/AISC 360-10.

\section{Introduction}

Steel plate girders are used to suspend the tower-type boilers in heavy power plants, the span length of which can exceed $40 \mathrm{~m}$ and the depth of sections can reach $8 \sim 10 \mathrm{~m}$. Such giant form is not generally possible in ordinary engineering structures. Besides the deep and narrow cross section, the support conditions of such girders shown in Fig. 1 are especially different from common cases. In heavy plants for tower-type boilers, the plate girders are directly installed over the arc bearing plate welded on the top cover of columns, which means that the ends of such girders are laterally unbraced and have no restraint against lateral deflection and twisting compared with ideal hinged supports and sliding supports. Thus, their stability behavior, i.e., the capacity against lateral-torsional buckling and the influencing factors, needs to be examined.

Theoretical study on LTB (lateral-torsional buckling) of beams started at the end of the 19th

Corresponding author: Yiyun Zhu, Ph.D. candidate, research fields: steel structures and beam theory. century. Prandtl and Michell studied the LTB problem of high and narrow beams with rectangular cross section [1]. Bleich [2], Vlasov [3] and Timoshenko and Gere [4] systematically studied the stability theory of thin-walled members and established the foundation of classical stability theory of thin-walled structure, which is commonly referred to as the "traditional theory" [5]. On these bases, researchers established their own theory decades after. Finite element methods are also introduced to this field in the 1970s [6-8]. In the 1990s, many researchers [9-12] carried out in-depth researches on the theory of nonlinear elastic stability of thin-wall members and proposed the corresponding model, which abandoned the simplified assumptions of existing theories. Zhang and Tong [13] derived the strain energy formula considering nonlinear normal and shear strain, including nonlinear transverse normal strain, and affirmed the validity of the "traditional theory". Mohri et al. [14-16] established the calculating stability model of thin-walled members considering the nonlinear effects in elastic range, and the deformation field is built according to the Vlasov 


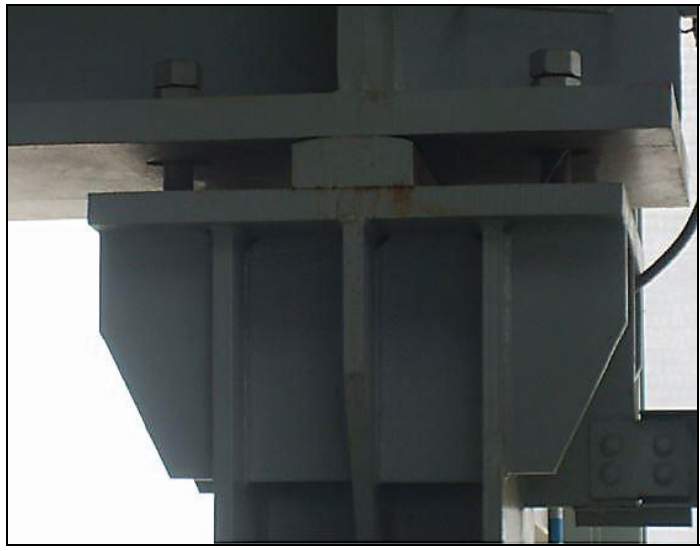

Fig. 1 Support of plate girders for tower-type boilers.

assumptions, considering the nonlinear strain tensor.

Some discussions on design concepts about LTB can be found in literatures in recent years. Suryoatmono and Ho [17] researched on the moment modification factor of simply supported beams, corrected the calculating formulas of equivalent bending moment provided by American National Standard ANSI/AISC 360-10 [18] when the moment is not in a linear variation. Lim et al. [19] studied on the elastic LTB of I-shaped steel beam under different proportions of end moments with varied end constraints, and the improved formula they gave has smaller error than those of ANSI/AISC 360-10 [18] and SSRC (Structural Stability Research Council) Guide [20]. Trahair and Hancock [21] derived a simplified method to calculate the out of plane failure of steel members, and the critical loads they reached on simply supported beam under four kinds of loading and fixed beam under a bending moment are a little higher than AS4100-1998 [22]. Kumar and Samanta $[23,24]$ used ABAQUS [25] to simulate the overall stability of simply supported beams under different loading, finding the SSRC Guide [20] overestimated the critical buckling load of short beams, which is generally controlled by torsion of web plates. With the development of testing and simulation technology, full-scale tests on plate girders and corresponding nonlinear finite element analysis with actual imperfections are performed by researchers, while most attention has been put on moment-shear interaction, local-global interactive buckling and post buckling performance of the girders.

Almost all the practical researches on stability behavior of plate girders are based on the premise that the objects are laterally restrained along the span or on both support ends at least. As for the related specifications, ANSI/AISC 360-10 has no specific provisions for short deep flexural members laterally unbraced along the span. This research is to get an insight into the stability behavior of such members and its influencing factors, provide a simple FE (finite element) model and discuss on the applicability of code provisions. Stability test and numerical study indicate that the existing standards can barely guide the design process of such girders. Moreover, the initial geometrical imperfections, which are commonly ignored by code provisions, may reduce the bearing capacity in such cases and even lead to unexpected failure.

\section{Design Concepts in ANSI/AISC 360-10}

\subsection{Basic Equation of Buckling Moment}

According to the elastic stability theory, the buckling moment of simply supported thin-walled beams subjected to transverse loads $\left(M_{c r}\right)$ can be expressed as following [26]:

$$
\begin{gathered}
M_{c r}=C_{1} \frac{\pi^{2} E I_{y}}{l^{2}}\left[-C_{2} a+C_{3} \beta_{y}+\right. \\
\left.\sqrt{\left(-C_{2} a+C_{3} \beta_{y}\right)+\frac{I_{w}}{I_{y}}\left(1+\frac{G J l^{2}}{\pi^{2} E I_{w}}\right)}\right]
\end{gathered}
$$

where, $E, G$ are Young's modulus and shear modulus, respectively, $I_{y}$ is the second moment of area about weak axis, $J$ is St.Venant constant, $I_{\omega}$ is warping inertia moment, $a$ is vertical distance between loading point and shear centre, $\beta_{y}$ is dissymmetry coefficient. The three factors $\left(C_{1}, C_{2}, C_{3}\right)$ are related to form and position of transverse loads and can be derived from the total potential energy equation of the "traditional theory". 
Eq. (1) is the basis of code provisions about elastic LTB. The American National Standard [18, 20], ISO Code [27], Eurocode 3 [28] and Chinese Code [29] take same or very close value of $C_{1}, C_{2}$. For doubly symmetric members $\left(\beta_{y}=0\right)$ and $C_{3}$ has no influence, approximate elastic buckling moment can be achieved by different codes. Pi et al. [30] and Trahair [31] provided $C_{1}, C_{2}$ as follows:

- For uniform moment, $C_{1}=1.00, C_{2}=0$;

- For uniformly distributed load, $C_{1}=1.13$, $C_{2}=0.46$

- For concentrated load at mid-span, $C_{1}=1.35$, $C_{2}=0.55$.

Eq. (1) is obviously not suitable for practical use, while design concepts in codes are based on simplified methods for calculation.

\subsection{Code Provisions}

ANSI/AISC 360-10 supersedes Load and Resistance Factor Design and Allowable Stress Design, released in 2010. The case of uniform moment along unbraced length $L_{b}$ is employed as the basic loading case in provisions about LTB.

If $L_{b}$ is below the plastic limiting unbraced length $L_{p}$, the limit state of LTB does not apply for doubly symmetric compact I-shaped members. The bending strength is calculated according to the section strength in Eq. (F2-1) of the code:

$$
M_{n}=M_{p}=F_{y} Z_{x}
$$

If $L_{b}$ exceeds the elastic limiting unbraced length $L_{r}$, the elastic LTB governs. The bending strength in this case is given by Eq. (F2-3):

$$
M_{n}=F_{c r} S_{x} \leq M_{p}
$$

Then, if $L_{p}<L_{b} \leq L_{r}$, the limit state is inelastic failure. The nominal flexural strength is the result of linear interpolation between section strength and the limit state of yielding, read from Eq. (F2-2):

$$
M_{n}=C_{b}\left[M_{p}-\left(M_{p}-0.7 F_{y} S_{x}\right)\left(\frac{L_{b}-L_{p}}{L_{r}-L_{p}}\right)\right] \leq M_{p}
$$

where, F2-1, F2-3, F2-2 are labels in the AISC 360-10 Code [18].

The moment modification factor $C_{b}$ should be applied when the moment distribution is nonuniform. Limiting unbraced length $L_{p}$ and $L_{r}$ are calculated according to the section parameters.

\subsection{Applicability Discussions}

Code provisions of ANSI/AISC 360-10 have explicit physical meanings and simply explain the influence of moment distribution $\left(C_{b}\right)$ and residual stress $\left(F_{r}\right)$ to its users.

There is a basic assumption in design process that the members are ideally restrained against twisting and lateral deflection on support ends to meet the boundary conditions of design concepts, so unbraced length $L_{b}$ equals the span length for ideal simply supported beams. There are no specific provisions for flexural members with laterally unbraced ends.

The geometrical size of cross sections is neglected in the basic mechanical model, so the height of load application points does not appear in the equations. It can be acceptable for slender members, but not suitable for the objects discussed in this paper.

Most of all, the initial geometrical imperfection is ignored in the equations, because it makes very limited difference in common circumstances and is difficult to measure. But when it comes to plate girders with laterally unbraced ends, combined with high load application points, geometrical imperfection may significantly affect the states.

\section{Experimental Design}

\subsection{Material and Girder Description}

Three girders were fabricated from two different steel plates with Q235 (nominal yielding stress is $235 \mathrm{MPa}$ ) structural steel, which were $12 \mathrm{~mm}$ thick for flange plates and $4 \mathrm{~mm}$ for web and stiffeners. The real properties of materials were measured by simple tension tests. For the purpose of numerical simulations, the measured stress-strain curve was modelled with a 

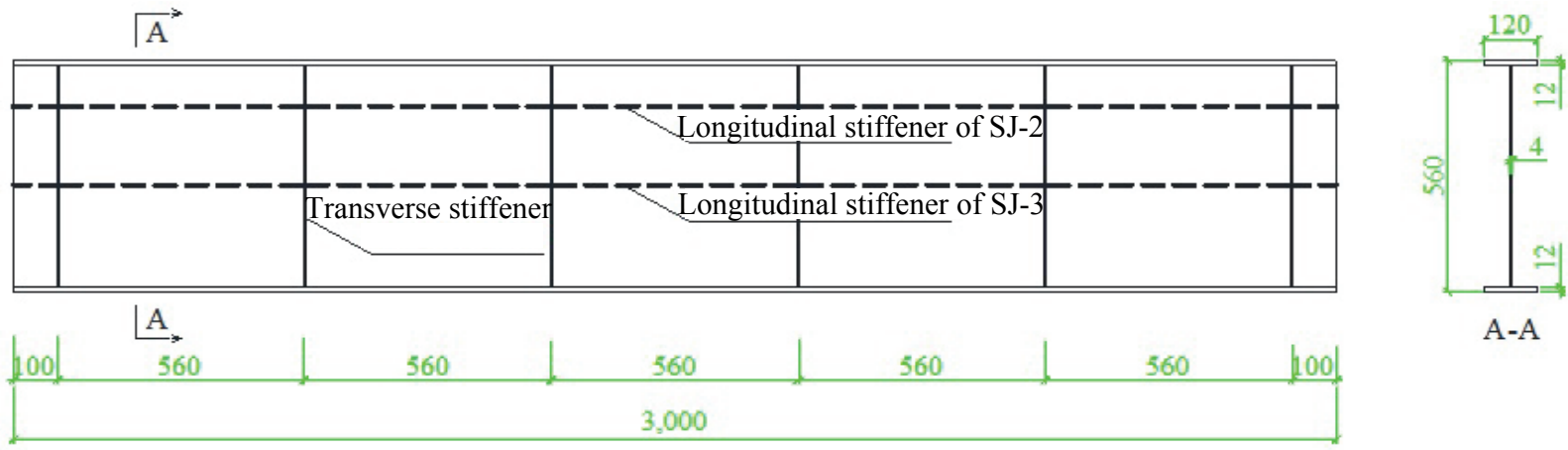

Fig. 2 Test specimens and dimensions (unit: $\mathbf{m m}$ ).

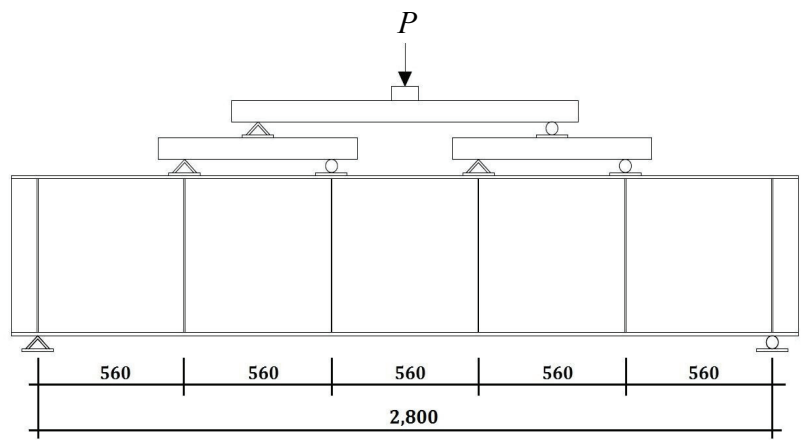

Fig. 3 Sketches of load and support (unit: $\mathbf{m m}$ ).

2-linear curve, i.e., "bilinear isotropic plasticity" to be the constitutive models, where Young's modulus $E=206 \mathrm{GPa}$, tangent modulus $E_{t}=6,100 \mathrm{MPa}$, yield stress $F_{y}=265 \mathrm{MPa}$.

The tested girders shown in Fig. 2 were scale models of real plate girders, simplified in mechanical design.

The tested girders had total length of $3,000 \mathrm{~mm}$ and span length of $2,800 \mathrm{~mm}$ (100-mm extension was given on each side). The cross sections of three specimens were the same, where $h=560, t_{w}=4$, $b_{f}=120, t_{f}=12 \mathrm{~mm}$, and 4-mm-thick transverse stiffeners were located on every one-fifth point of the span and both ends. The arrangements of 4-mm-thick longitudinal stiffeners were the only difference between three specimens.

SJ-1 had no longitudinal stiffener whereas the specimens SJ-2 and SJ-3 had longitudinal stiffeners. Specifically, the vertical distance from compression flange in SJ-2 and SJ-3 were $98 \mathrm{~mm}$ and $288 \mathrm{~mm}$, respectively. Stiffeners can enhance the capacity of girders, but are neglected in code provisions about LTB.

\subsection{Load and Support}

A sketch of load and support conditions is shown in Fig. 3. The load $P$ was applied from a hydraulic jack and was distributed into four even transverse loads ( $P / 4$ each) on one-fifth points of the span, using rigid distribution beam. Stress concentration is prevented by transverse stiffeners and rigid plate on loading points. It is obvious that vertical support reaction on each side was $P / 2$.

In heavy plants for tower-type boiler, loads from the boiler are applied from hanger rods to the girders and are commonly simplified as concentrated loads over compression flange in design and research process [32]. Supports of single girder were made of an equilateral web angle and a round bar, respectively, without any restraint against twisting and lateral deflection along the whole span of the girder, to simulate the actual boundary condition.

\subsection{Critical Load Calculation}

Plate girders are often made to be deep and narrow, considering the economic efficiency. Thus, the local instability and yielding of the web plates should be taken into account.

The specimens can be classified as "doubly symmetric I-shaped members bent about their major axis with compact flange and noncompact web" according to Chapter B4 of ANSI/AISC 360-10 and should be examined according to Chapter F4. Code provisions about such sections are similar with compact sections introduced above, where the web 
plastification factor $R_{p c}$ is additionally included.

According to the provisions of ANSI/AISC 360-10, which is a simplified form of Eq. (1) and the unbraced length is supposed to be $2,800 \mathrm{~mm}$, the critical load that the specimens can bear is:

$$
P_{c r, A I S C}^{2,800}=492.6 \mathrm{kN}
$$

As discussed in Section 2.3, the code can not provide authentic results for plate girders with laterally unbraced ends, the critical load acquired above is for reference only.

\subsection{Discussions}

There are no provisions about the design and stress/buckling calculation of transverse stiffeners in ANSI/AISC 360-10. For plate girders without any lateral restraint along the span, the resisting force against twist of the cross sections can only be provided by bending stiffness of the transverse stiffeners and that may not be enough in this case, especially for transverse stiffeners over the supports, which bear the largest compression, bending and torsion loads, and may cause serious consequences if a single piece of them is wrecked. The twist of the cross sections on support plan will break the basic assumption of boundary condition.

Rules to cover incomplete end restraint are available in some codes, such as British Standard BS5950-1:2000 [33], in which the calculating length of such beam is its span length plus two times the height. Those provisions can be adopted in design process. In this case, the unbraced length $L_{b}=3,920 \mathrm{~mm}$, and it exceeds the elastic limiting unbraced length $L_{r}$, so the elastic LTB governs in this case.

So, the suggested critical load is:

$$
P_{c r, A I S C}^{3,920}=345.5 \mathrm{kN}
$$

which becomes much lower.

\subsection{Instrumentation}

Loading and measuring facilities were set up as shown in Fig. 4. A block of stone sat beside to prevent

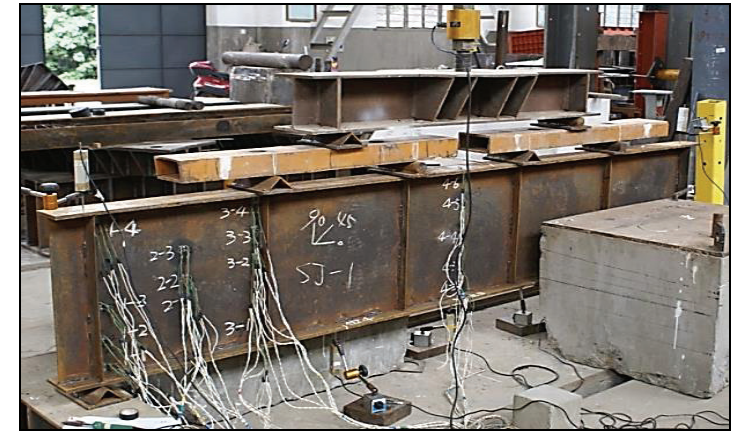

Fig. 4 Loading and measuring facilities.

the specimen and facilities from falling.

Strains and deflections were continuously measured as the test progressed.

The mid-span deflection of the girder was measured by displacement transducers, to monitor the overall performance of the girders and for verification of the numerical models.

Uni-axial strain gages were set along the middle section of the girders, on web grid and both flanges, subjected to bending. To monitor the local buckling and yielding of web plate, rosettes were set in the web grid near the support and mainly distributed in the tension field of web plates subjected to shear [34].

\section{Test Results}

\subsection{Behavior of the Tested Girders}

Warping was observed from the extension edge of web in SJ-1, when load $P$ was approaching to $320 \mathrm{kN}$, caused by local distortional buckling, and the data recorded from rosettes near the support showed that the material in this region has advanced to plastic stage. But material along the middle cross section remained in elastic stage till the test ends, told from the uni-axial strain gauges, and the development of mid-span deflection kept linear approximately, which means the nonlinearity of the whole girder was not obvious. Reached the load of $360 \mathrm{kN}$, the girder suddenly collapsed, laterally leaned, and completely lost capacity. The cross section in the support plane on one side was obviously twisted, while the center of rotation was at the center of the bottom flange. Half of the transverse stiffener over the support in failure 
section was compressed to buckle, and the opposite half tore from the bottom.

The loading process and stability behavior of SJ-2 and SJ-3 were very similar with that of SJ-1. Local distortional buckling and yielding occurred at the edge web plates before the whole girder buckled. Three specimens failed in the same mode, along with the wreck of transverse stiffeners over the supports. The critical load of SJ-2 and SJ-3 were both $370 \mathrm{kN}$, $10 \mathrm{kN}$ higher than that of SJ-1.

The failure mode of SJ-3 on local and overall scale is shown in Fig. 5, on behalf of all three specimens.

\subsection{Discussions on Stability Behavior of Specimens}

The stability behavior and failure mode of the specimens were widely different from typical LTB mode of simply supported thin-walled beams in these aspects:

- The failure mode of the specimens was lateral deflection and twist of the ends, which is prevented from happening by lateral braces in common cases;

- Nonlinearity behavior of the whole girders were not obvious before buckling;

- The buckling of whole members happened in a sudden, while the girders lost capacity completely thereupon and seem to be sensitive to imperfections; Those are features of bifurcation buckling, instead of neutral equilibrium.

The main factors are as follows:
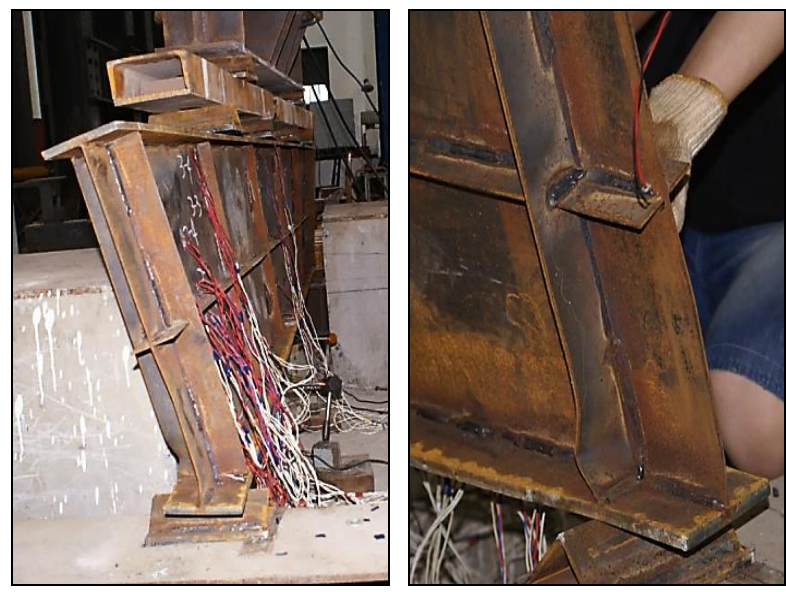

Fig. 5 Failure mode of the specimens.
- The cross sections are designed to be deep and narrow that equals to high load application points. Thus the second-order effects in plate girders are much more significant;

- When initial sweep and twist exists, lateral deflection increases continuously and tends to be very large without much resistance as the applied load approaches critical load, which causes serious eccentric compression on transverse stiffeners over the support;

- One of the basic assumptions of the "traditional theory" and design concepts is that the beam is laterally restrained on both support ends, which means that lateral deflection and twist about the longitudinal axis in support plane are prevented. But the plate girders discussed in the article do not satisfy this. The resisting force against twist of the end sections were only provided by bending stiffness of the transverse stiffeners, which has been proved insufficient by the tests for those over the supports, i.e., the boundary conditions were broken as the cross section in support plane swept and twisted.

With the combined effect of the factors above, the whole girder buckles along with the wreck of the transverse stiffeners on support ends.

\subsection{Comparative Results with Code Provisions}

The experimental results of three specimens fall in the range of $360 \sim 370 \mathrm{kN}$. But the estimation of critical load is $492.6 \mathrm{kN}$ in Eq. (2), and the estimating failure mode is inelastic failure according to the ANSI/AISC code, which obviously mismatch with the tests. The contributing factors leading to this result have been discussed above.

Therefore, the estimation of stability behavior according to provisions of the ANSI/AISC code can not be fully adopted for plate girders with laterally unbraced ends. Provisions about stress and buckling calculation of transverse stiffeners, especially those in support planes, are badly needed.

Rules to cover incomplete end restraint in British 
Standard have been adopted in design process, and the estimation was adjusted to $345.5 \mathrm{kN}$ in Eq. (3), and the estimating failure mode is elastic LTB, which seems to be more reasonable.

\section{Numerical Simulations}

A nonlinear finite element analysis was carried out using commercial FEA (finite element analysis) software ANSYS 14.5 [35]. The combined effects of plasticity, residual stress and geometrical imperfections are considered to explain the experimental phenomena.

\subsection{General}

The nonlinear FE model is established by following steps:

(1) Build an ideal model with shell elements, mesh the flange plates and web plates before stiffeners, to ensure that the element number of the cross section starts from 1 . Then, run the macro file to generate the initial residual stress data on cross section;

(2) Build the same model as Step (1), and proceed EBA (eigenvalue buckling analysis);

(3) Build the model for the third time, then apply the initial imperfections, read the first-order buckling mode from Step (2) to generate the shape of initial geometrical imperfections, set $1 / 1,000$ of total length $(3,000 / 1,000 \mathrm{~mm})$ as the maximum amplitude, according to the Chinese code for acceptance of constructional quality of steel structures GB50205 [36], and constrain all the degrees of freedom of nodes to apply the residual stresses model with no strain;

(4) Apply real boundary conditions and loads to proceed the nonlinear stability analysis.

\subsection{FE Modeling}

The shell element model proposed by Zhang and Tong [37] is used, as less assumptions are adopted in shell theory than beam theory, to get more precise results. Element type SHELL 181 is used for flanges and webs, which is a kind of four node elements with six degrees of freedom for each node, and applicable to nonlinear analysis with large deformation.

Transversal displacements about $x$ - and $y$-axis of nodes in supported positions on tension flange are restrained, in addition, the rigid body motion of beam in $z$-direction (longitudinal) is prevented by fixing the $z$-displacement of nodes on one side. These treatments in shell element modeling can satisfy the real boundary condition of the specimens in experimental tests. The maximum element width is $40 \mathrm{~mm}$. The ideal model of SJ-2 is shown in Fig. 6, colored by material types, for all three models.

\subsection{Models of Initial Imperfections}

Concentrated force of $80 \mathrm{kN}(P / 4)$ is applied at four points, to simulate real loading. The first order buckling mode provided from the elastic ideal model, shown in Fig. 7, is typical LTB mode of simply supported beam, which is not consistent with the experimental phenomena.

The corresponding load factors are obtained by EBA. The factor multiplied by the applied load $P$ equals the instability load of such buckling mode. The factors of first order buckling mode are 1.21, 1.25 and 1.26 for SJ-1, SJ-2 and SJ-3, respectively, so the instability load $P$ here would be $387 \mathrm{kN}, 400 \mathrm{kN}$ and $403 \mathrm{kN}$. The critical load obtained by EBA is the upper bound of nonlinear stability analysis.

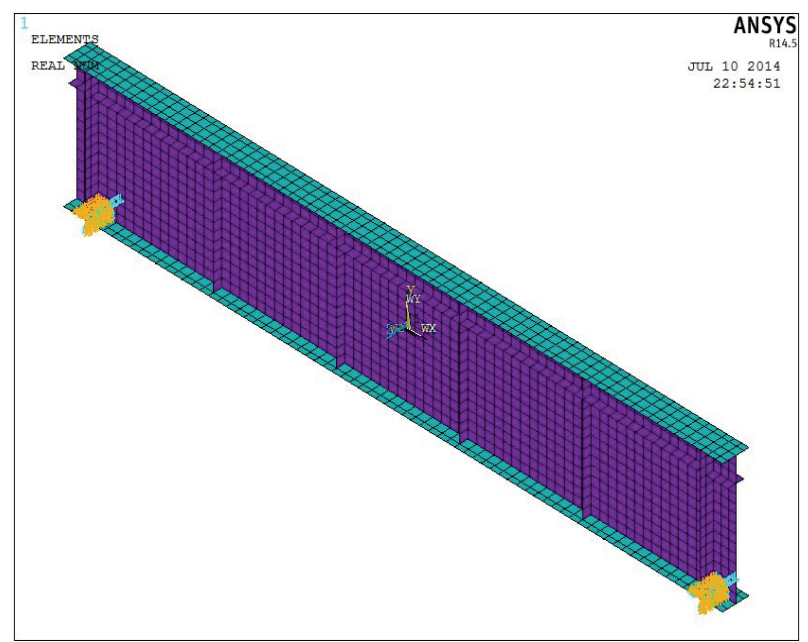

Fig. 6 FE modeling of SJ-2. 


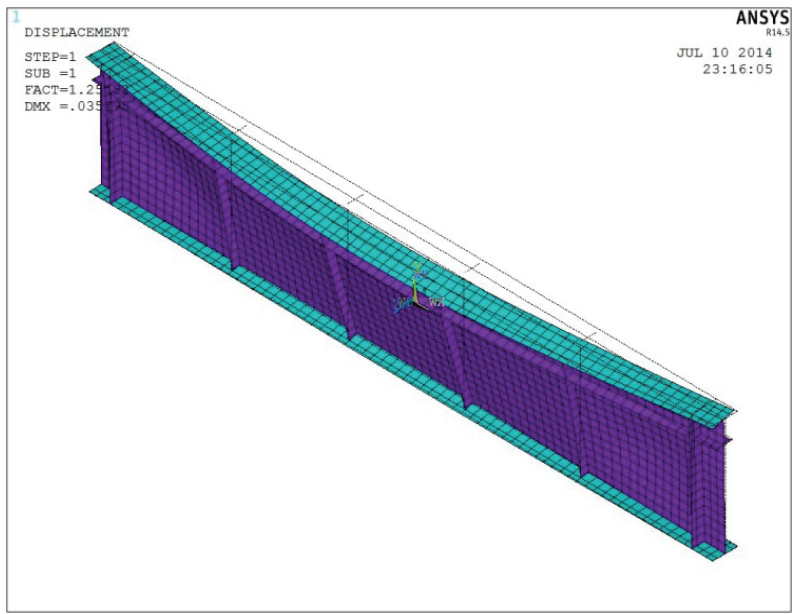

Fig. 7 First order buckling mode by EBA.

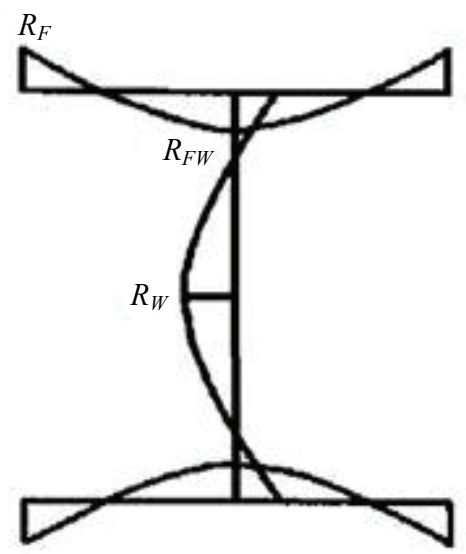

Fig. 8 Model of residual stress.

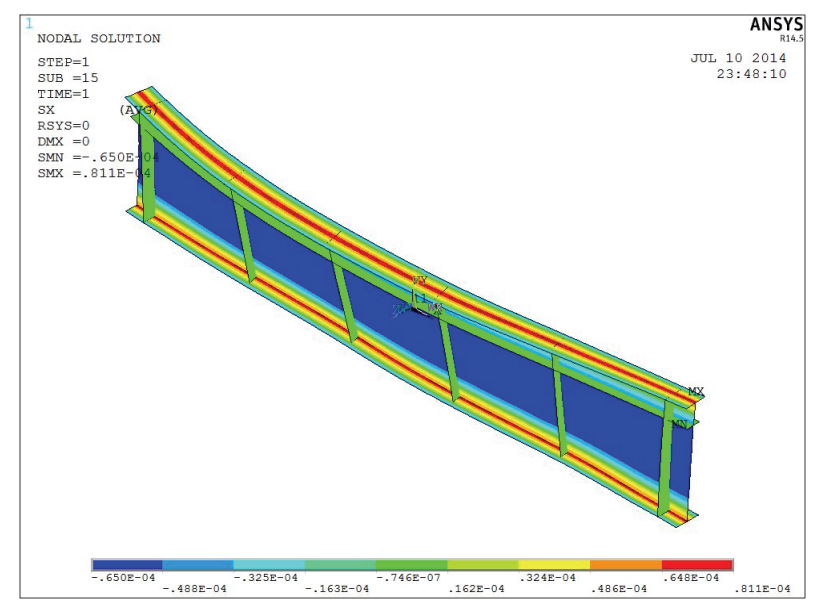

Fig. 9 Distribution of initial imperfections.

Residual stress reduces lateral stiffness and flexural rigidity of plate girders from overall perspective, and it advances the plates into local buckling and yielding. It shows that the existing of residual stress will affect the interaction between local buckling and beam failure. Parabolic model is adopted to describe it, which was proved to be more realistic. Cubic parabola distribution is taken for flanges and four times parabola for webs, meeting the self balance of plates, shown in Fig. 8, where $R_{F}, R_{F W}, R_{W}$ are calculated according to Ref. [38].

The geometric imperfections mean the initial bending produced in the manufacturing process in general, which is too complicating and difficult to be expressed in a precise manner. Through EBA above, deformation trend of the members in linear elastic stage can be obtained, and the geometric imperfections of specimens can be modeled with this trend, as a simplified way. The pattern of initial geometrical imperfections in this case is the fist-order buckling mode of the ideal model shown in Fig. 7, obtained by EBA, setting $3 \mathrm{~mm}$ as maximum amount of deformation.

Distribution of residual stress and initial geometrical imperfections along the girders can be seen in Fig. 9.

\subsection{Nonlinear Stability Analysis (Complete Model)}

Bilinear isotropic plasticity model is used to describe the material, and the static equilibrium is found by arc length method. Loading-deflection curve is obtained by postprocessor, to be used for model verification in the following discussions.

In general, stress distribution of the models with the increase of loads fits the test results well. Fig. 10 shows the distribution of von Mises stress just before the load $P$ reaches the peak value. The whole girder shows signs of eccentricity due to the increasing sweep and twist. Material near the support ends has yielded, and the transverse stiffener shown in the right view is about to wreck from the compression side, causing the collapse of whole girder.

Stability behavior (failure mode) of the models also meets the testing results very well, as shown in Fig. 11. The critical loads are $359 \mathrm{kN}, 371 \mathrm{kN}$ and $372 \mathrm{kN}$ for 


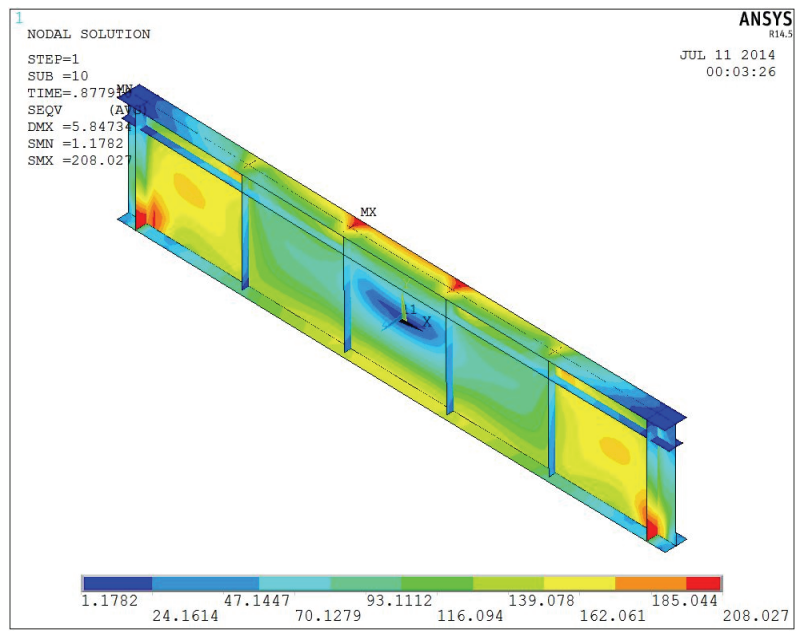

(a)

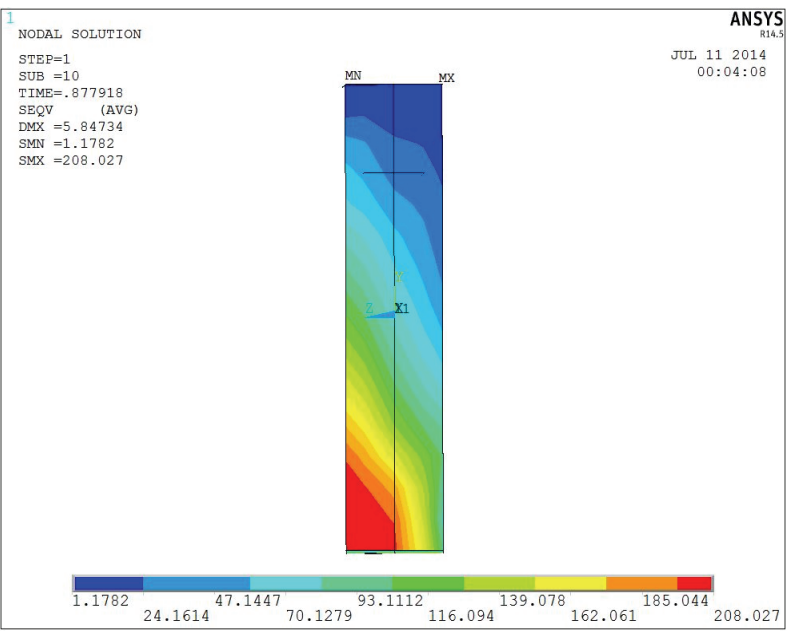

(b)

Fig. 10 Distribution of Von Mises stress before buckling: (a) the isometric view; (b) the right view.

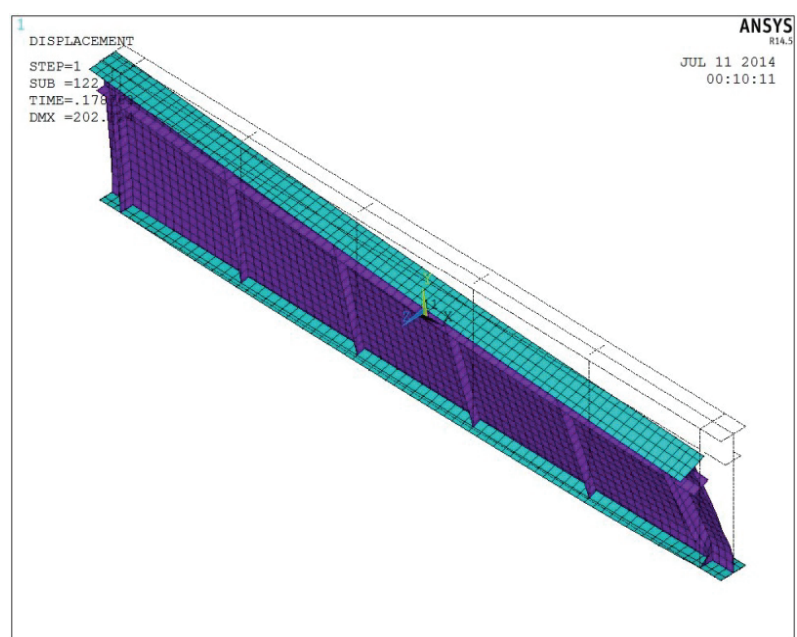

(a)

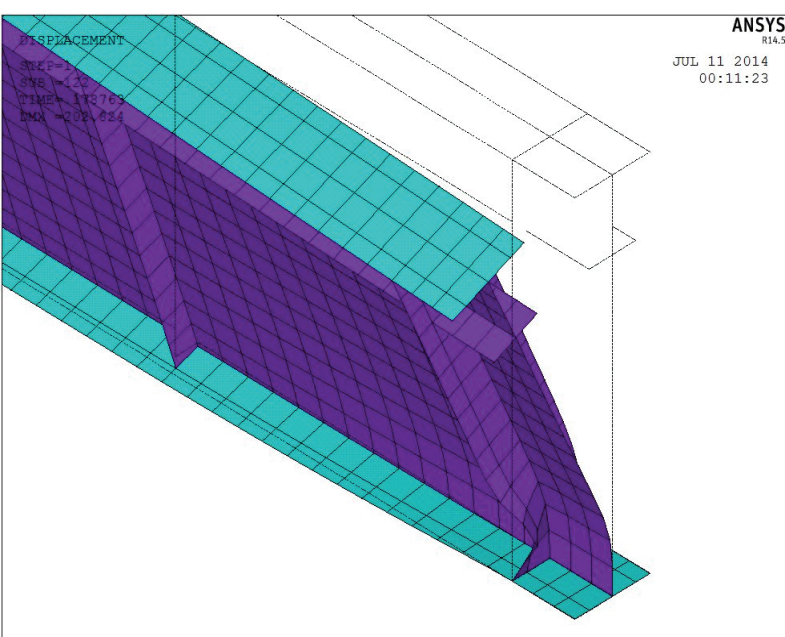

(b)

Fig. 11 Failure mode obtained by nonlinear stability analysis: (a) failure mode on overall scale; (b) failure mode on local scale.

SJ-1, SJ-2 and SJ-3, respectively, where the errors compared with the test results $(360 \mathrm{kN}$ for $\mathrm{SJ}-1$, $370 \mathrm{kN}$ for SJ-2 and SJ-3) are just $-0.28 \%,+0.27 \%$ and $+0.54 \%$.

\subsection{The "Degradation Models" with Zero Geometrical Imperfections}

The initial geometrical imperfection, as mentioned above, may have significant effect on the stability behavior. To prove that, "degradation models" are established, in which only the modeling of initial geometrical imperfections has been removed from the "complete models" built above.
The "degradation models" lead to inelastic failure instead of elastic buckling, and the critical loads are much higher than that of the "complete models", which are $514 \mathrm{kN}, 516 \mathrm{kN}$ and $516 \mathrm{kN}$, respectively. These results are close to the estimation according to Eq. (2). Therefore, the sensitiveness to geometrical imperfections of the specimens has been revealed.

The results obtained from the "degradation models" indicate that the existing of initial geometrical imperfections reduced the carrying capacity of the specimens, and most importantly, leaded to changing on failure mode, which could not be estimated by normal design process. 


\subsection{Comparative Results and Model Verification}

Results of different kind of analysis are listed in Table 1, to make the standpoints clear.

The "complete model", for nonlinear finite element stability analysis with a combined effect of plasticity, residual stress and geometrical imperfections, is verified by the test, and all the initial imperfections are built with simplified model to reduce the quantity of work. The significant effects of boundary condition and geometrical imperfection are discussed and proved, as well.

It can be found that, when it comes to the interaction between local buckling and column failure of thin-walled compression members, geometrical imperfection becomes a major factor [39]. Obviously, plate girders with deep sections and laterally unbraced ends studied in this paper have similar properties.

In addition, according to the results of SJ-1, although the longitudinal stiffeners are neglected in code provisions, it is still suggested to be set in such girders to enhance the stability of whole members.

The development of mid-span deflection can explain the overall performance of specimens. To further illustrate the problem, results of Euler-Bernoulli beam theory and Timoshenko beam theory are also presented, which are both first order beam theories. The loading-deflection curves are shown in Fig. 12, to verify the numerical models.

Because of the deviation of installation and loading, additional out of plane displacement occurs on the specimens, reducing the flexural rigidity in plane. So, the deflections measured from the tests are always larger than those from FEA, and the increasing trend is not so stable.

The numerical models show features of bifurcation buckling in this case, instead of neutral equilibrium in common circumstances explains the instantaneity of failure in tests and its sensitiveness to the geometrical imperfections, which can be very dangerous in real constructional steel structures. Much attention should be paid for designing of such girders.

\section{Model Adjustments}

Sridharan [40] studied the local-global interactive buckling on thin-walled structures, finding that additional stiffeners can offset the influence of initial imperfections. In this case, the bending stiffness of the

Table 1 Critical loads and failure mode (units in $\mathrm{kN}$ ).

\begin{tabular}{lllllll}
\hline Item & $P_{c r, A I S C}^{2,800}$ & Degradation models & $P_{c r, A I S C}^{3,920}$ & EBA & Complete models & Tests \\
\hline SJ-1 & & 514 & & 387 & 359 & 360 \\
SJ-2 & 492.6 & 516 & 345.5 & 400 & 371 & 370 \\
SJ-3 & & & 403 & 372 & 370 \\
\hline Failure mode & Inelastic failure & & LTB (lateral-torsional buckling) & Buckled ends &
\end{tabular}

EBA: First order buckling mode obtained by EBA (eigenvalue buckling analysis).

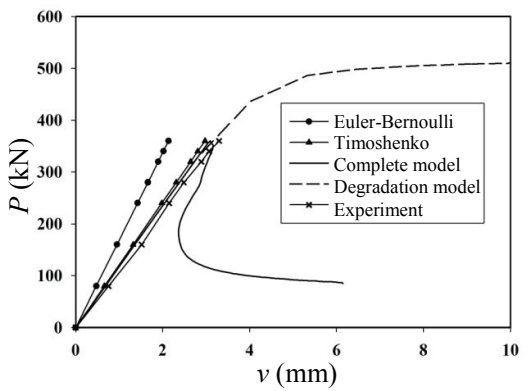

(a)

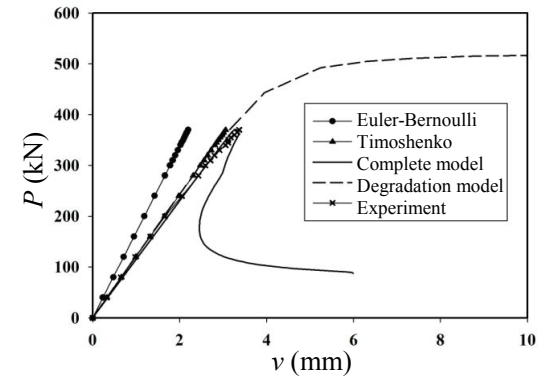

(b)

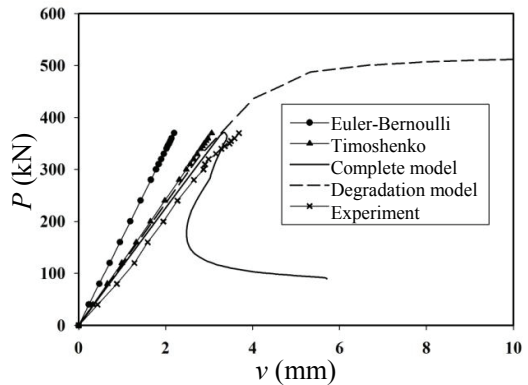

(c)

Fig. 12 Failure mode obtained by nonlinear stability analysis: (a) mid-span deflection of SJ-1; (b) mid-span deflection of SJ-2; (c) mid-span deflection of SJ-3. 


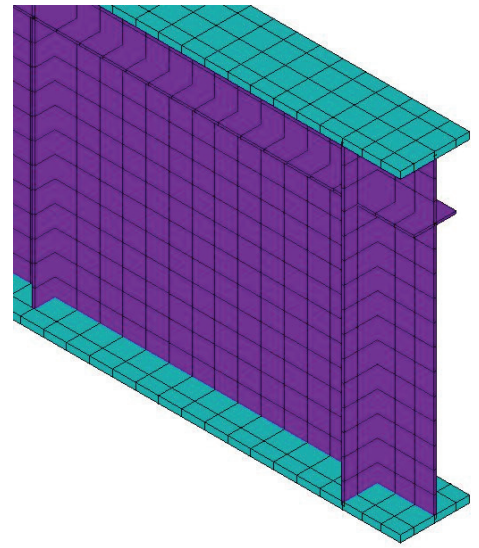

(a)

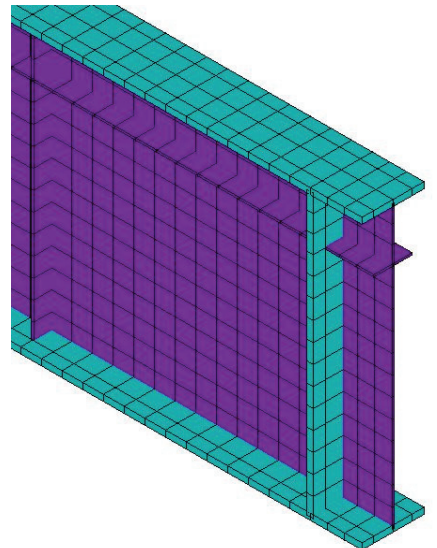

(b)

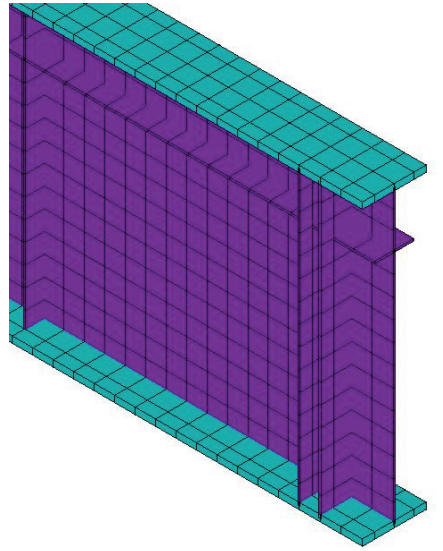

(c)

Fig. 13 Model adjustments on mechanical design of transverse stiffeners over the supports: (a) original model; (b) Model A; (c) Model B.

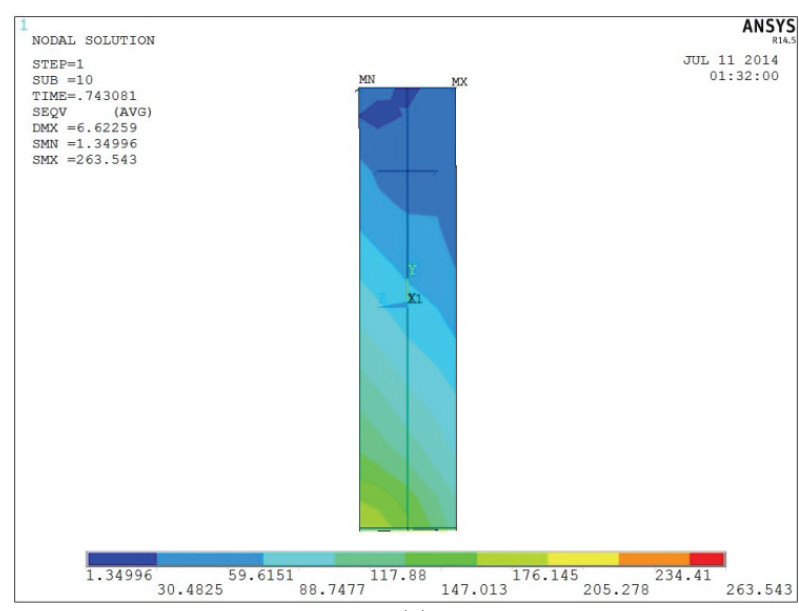

(a)

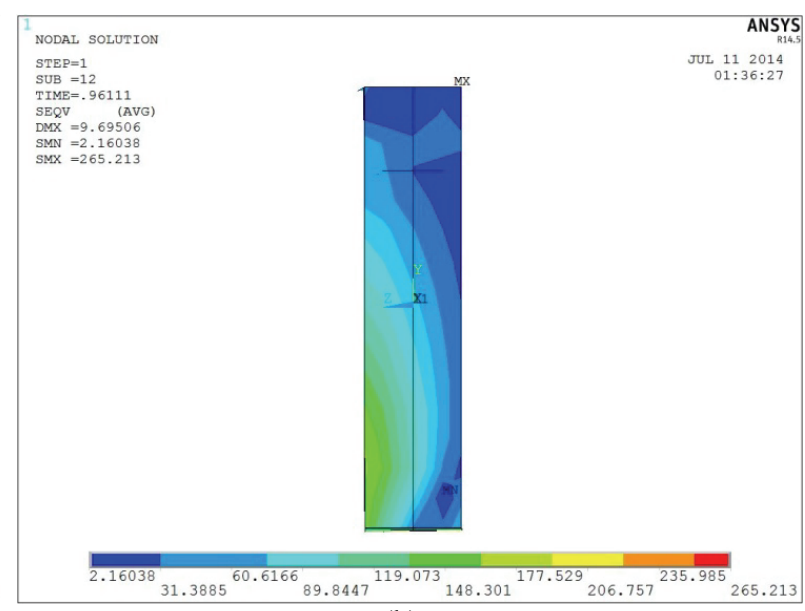

(b)

Fig. 14 Distribution of Von Mises stress of the adjusted models: (a) Model A; (b) Model B.

transverse stiffeners over the supports is the main force against twist of the cross section, and the girders are sensitive to geometrical imperfections. So, the verified model is used to adjust the mechanical design of transverse stiffeners over the supports based on the original model of SJ-2, and the nonlinear stability analysis introduced above is performed on the adjusted models to seek for some positive effects. There are two adjustment schemes, shown in Fig. 13:

(1) Model A thickens the corresponding stiffeners from $4 \mathrm{~mm}$ to $12 \mathrm{~mm}$, which means these stiffeners have the same mesh (color) with flange plates;

(2) Model B sets additional stiffeners $40 \mathrm{~mm}$ away from the original ones, and the thickness of the additional stiffeners is still $4 \mathrm{~mm}$. The adjustment schemes strengthened the cross section in support plans without adding new element and material types, and they have nearly no increase on steel consumption.

The first order buckling modes are the same for both adjustment schemes. The corresponding load factors are $1.41(451 \mathrm{kN})$ and $1.38(441 \mathrm{kN})$ for Models A and B, respectively. Compared to that of the original model valued $1.25(400 \mathrm{kN})$, the adjusted models have $12.8 \%$ and $10.4 \%$ increase, respectively. Both adjustment schemes have large enhancement.

\subsection{Stability Behavior}

The nonlinear stability analysis introduced in Section 5.4 is performed on the adjusted models. Fig. 14 shows the distribution of Von Mises stress just before failure. The eccentricities on transverse 
stiffeners over the supports are greatly decreased and far from wreck compared to the situation shown in Fig. 10, which means that the effect of geometrical imperfections has been offset to some extent.

Most importantly, the failure mode of adjusted models meets the typical LTB mode of simply supported beam, without much leaning at the end sections and wreck of transverse stiffeners, shown in Fig. 15. Model A with thicker stiffeners shows better resistance against sweep of the top flange because of the promotion on lateral bending stiffness. And Model $B$ with additional stiffeners alongside original ones provides better torsion stiffness on support ends, compared to the situation shown in Fig. 11. The cross sections in support planes are not obviously twisted, while the assumptions of design concepts can be more

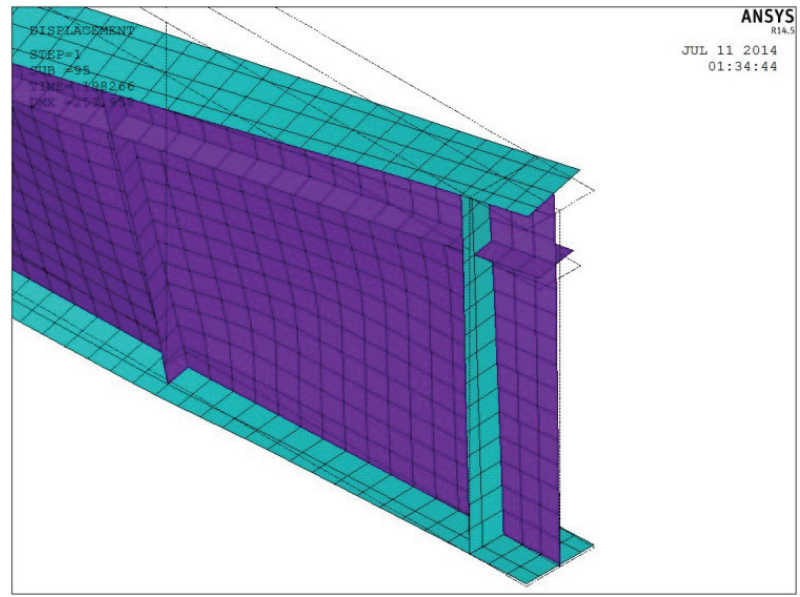

(a)

acceptable.

Meanwhile, the critical loads are raised to $445 \mathrm{kN}$ and $423 \mathrm{kN}$ for Models $\mathrm{A}$ and $\mathrm{B}$, respectively, compared to that of the original model, valued $371 \mathrm{kN}$, the adjusted models have $19.9 \%$ and $14.0 \%$ increase. The increase on critical load is higher than that obtained from EBA, because the influence of imperfections is effectively offset, thus the resistance against lateral deformation has been greatly improved.

\subsection{Load-Deflection Curve}

The load-deflection curves of the adjusted models are shown in Fig. 16, along with that of the original model of SJ-2 built above, to show the effect of adjustments on overall stability behavior. The ductility of girders has limited improvement, since features of

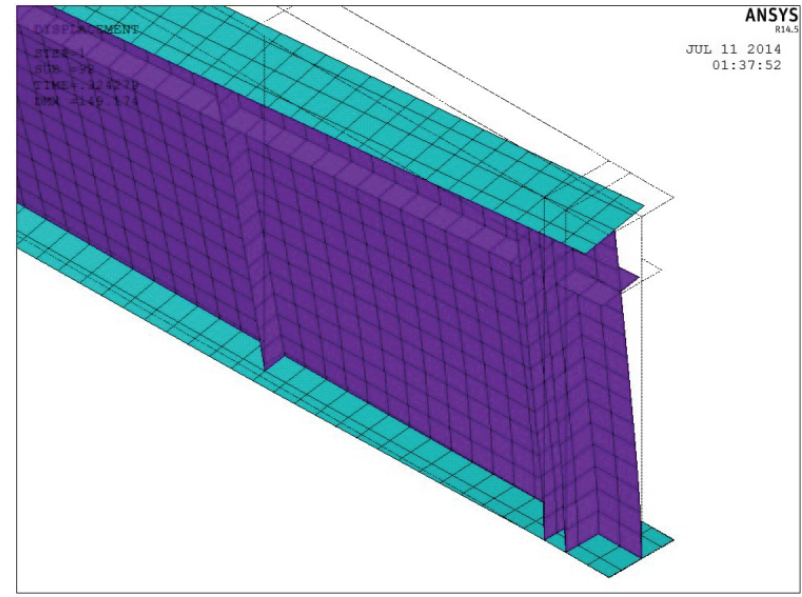

(b)

Fig. 15 Failure mode of the adjusted models: (a) Model A; (b) Model B.

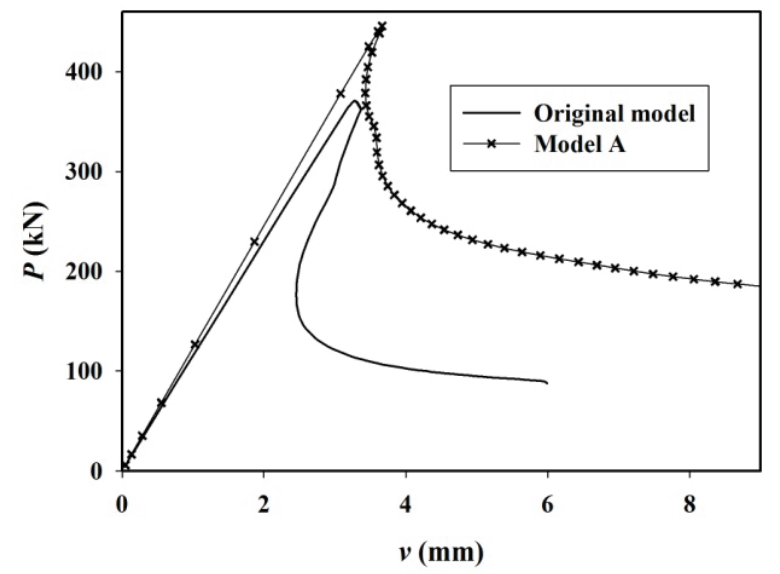

(a)

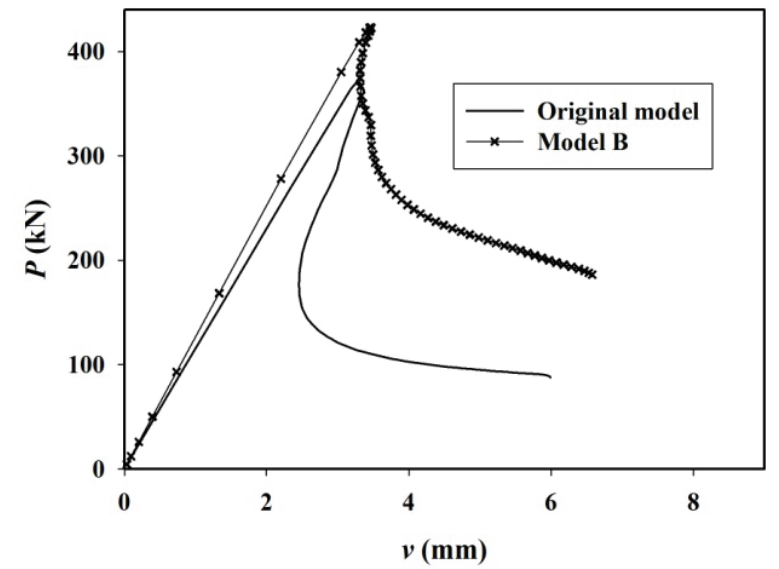

(b)

Fig. 16 Load-deflection curve compared to the original model: (a) the isometric view; (b) the right view. 
bifurcation buckling are inevitable once initial geometrical imperfections are considered. The failure of the girders will still be instantaneous.

\subsection{Effect of Adjustments}

The adjustments on mechanical design of transverse stiffeners over the supports have very positive effect on resistance against lateral deformation, especially on support ends of the girders, and they greatly enhance the overall bearing capacity. Thicker and additional transverse stiffeners can effectively offset the influence of initial geometrical imperfections locally in stiffened regions. Thus, the rigid frame assumption and assumption on boundary conditions of ideal simply supported thin-walled beam adopted by the "traditional theory" and design concepts can be better satisfied, to make the code provisions more applicable on the objects.

\section{Conclusions}

Tests were performed to get an insight into the stability behavior of plate girders with laterally unbraced ends and its influencing factors. A simple numerical model was defined to build and fit well with the experimental results.

Lacking of lateral restraint, especially on support ends, interacts with high load application points and geometrical imperfections. They can significantly reduce the carrying capacity of plate girders and even lead to instant and complete failure from support ends. If the girders have to be designed so, some additional suggestions can be provided:

- The deflection calculated through first order theories should be amplified;

- Real beams are not perfectly straight, so the design bending strength should have enough safety margin for those imperfections;

- Although the stiffeners are neglected in code provisions about LTB, they are still suggested to be well set in such girders because they have big effects actually;
- Rules to cover incomplete end restraint are available in some codes. Those provisions can be adopted in design process;

- Thicker and additional transverse stiffeners at the edge of girders can provide better resistance against lateral deformation and effectively offset the influence of imperfections.

\section{Research Expectations}

The research should be extended to monosymmetric sections, T-sections, etc., and other load conditions should be studied. With a wide set of specimens, computational and statistical analyses will be performed to achieve reliable conclusions and to give design proposals about stability behavior of giant plate girders under various loading with any boundary conditions.

\section{Acknowledgments}

The authors gratefully acknowledge sponsors of this research: National Science Foundation of China (No. 51278296).

\section{References}

[1] Kosmatka, J. B. 1993. "Flexure-Torsion Behavior of Prismatic Beams. I-Section Properties via Power Series." AIAA (American Institute of Aeronautics and Astronautics) Journal 31 (1): 170-9.

[2] Bleich, F. 1952. Buckling Strength of Metal Structures. New York: McGraw-Hill Book Co.

[3] Vlasov, V. Z. 1961. Thin-Walled Elastic Beams. 2nd ed. Washington, D.C.: National Science Foundation.

[4] Timoshenko, S. P., and Gere, J. M. 1961. Theory of Elastic Stability. 2nd ed. New York: McGraw-Hill Book Co.

[5] Tong, G., and Zhang, L. 2003. "An Analysis of Current Stability Theories for Thin-Walled Members." Advances in Structural Engineering 6 (4): 283-92.

[6] Johnson, C. P., and Will, K. M. 1974. "Beam Buckling by Finite Element Procedure." Journal of the Structural Division 100 (3): 669-85.

[7] Nethercot, D. A. 1975. "Inelastic Buckling of Steel Beams under Non-uniform Moment." Structural Engineering 53 (2): 73-8.

[8] Nethercot, D. A., and Trahair, N. S. 1976. "Inelastic Lateral Buckling of Determinate Beams." Journal of the 
Structural Division 102 (4): 701-17.

[9] Trahair, N. S., and Bild, S. 1990. "Elastic Biaxial Bending and Torsion of Thin-Walled Members." Thin-Walled Structure 9: 269-307.

[10] Pi, Y. L., and Trahair, N. S. 1992. "Prebuckling Deflections and Lateral Buckling. I: Theory.” J. Struct. Eng. ASCE 118 (11): 2949-66.

[11] Pi, Y. L., and Trahair, N. S. 1992. "Prebuckling Deflections and Lateral Buckling. II: Applications." $J$. Struct. Eng. ASCE 118 (11): 2967-85.

[12] Trahair, N. S. 1996. "Laterally Unsupported Beams." Engineering Structures 18 (10): 759-68.

[13] Zhang, L., and Tong, G. S. 2004. "Flexural-Torsional Buckling of Thin-Walled Beam Members Based on Shell Buckling Theory." Thin-Walled Structures 42 (12): 1665-87.

[14] Mohri, F., Azrar, L., and Potier-Ferry, M. 2001. "Flexural-Torsional Post-buckling Analysis of Thin-Walled Elements with Open Sections." Thin-Walled Structures 39: 907-38.

[15] Mohri, F., Azrar, L., and Potier-Ferry, M. 2002. "Lateral Post-buckling Analysis of Thin-Walled Open Section Beams." Thin-Walled Structures 40: 1013-36.

[16] Mohri, F., Brouki, A., and Roth, J. C. 2003. "Theoretical and Numerical Stability of Unrestrained, Mono-symmetric Thin-Walled Beams." Journal of Constructional Steel Research 59: 63-90.

[17] Suryoatmono, B., and Ho, D. 2002. "The Moment Gradient Factor in Lateral-Torsional Buckling on Wide Flange Steel Sections." Journal of Constructional Steel Research 58: 1247-64.

[18] AISC (American Institute of Steel Construction, Inc.). 2010. ANSI A. AISC 360-10, Specification for Structural Steel Buildings. Chicago: AISC.

[19] Lim, N. H., Park, N. H., Kang, Y. J., and Sung, I. H. 2003. "Elastic Buckling of I-Beams under Linear Moment Gradient." International Journal of Solids and Structures 40: 5635-47.

[20] Galambos, T. V. 1998. Guide to Stability Design Criteria for Metal Structures. Hoboken: John Wiley \& Sons.

[21] Trahair, N. S., and Hancock, G. J. 2004. "Steel Member Strength by Inelastic Lateral Buckling." Journal of Structural Engineering 130 (1): 64-9.

[22] Standard Australia. 1998. AS4100-1998: Steel Structures. Sydney: Standard Australia.

[23] Kumar, A., and Samanta, A. 2006. "Distortional Buckling in Monosymmetric I-Beams." Thin-Walled Structures 44: 51-6.

[24] Kumar, A., and Samanta, A. 2006. "Distortional Buckling in Monosymmetric I-Beams: Reverse-Curvature Bending." Thin-Walled Structures 44: 721-5.

[25] Hibbitt, Karlsson and Sorensen, Inc. 2001. ABAQUS/Standard User's Manual. Vol. 1. Providence: Hibbitt, Karlsson and Sorensen, Inc.

[26] Chen, J. 2003. Stability of Steel Structures Theory and Design. Beijing: Science Press. (in Chinese)

[27] ISO (International Organization for Standardization). 1996. ISO/TV147, Steel Structures, Material and Design. Geneva: ISO.

[28] CEN (European Committee for Standardization). 1992. Eurocode 3: Design of Steel Structures: Part 1-1: General Rules and Rules for Buildings. Brussels: CEN.

[29] Ministry of Construction of the People's Republic of China. 2003. GB 50017-2003 Code for Design of Steel Structures. Beijing: China Planning Press.

[30] Pi, Y. L., Trahair, N. S., and Rajasekaran, S. 1992. "Energy Equation for Beam Lateral Buckling." Journal of Structural Engineering 118 (6): 1462-79.

[31] Trahair, N. S. 1993. Flexural-Torsional Buckling of Structures. London: E\&FN Spon.

[32] Evans, H. R., and Moussef, S. 1988. "Design Aid for Plate Girders." Proceedings of the Institution of Civil Engineers 85 (1): 89-104.

[33] British Standards. BS 5950-1:2000-Structural Use of Steelwork in Building — Part 1. London: British Standards.

[34] Basier, K. 1961. "Strength of Plate Girders under Combined Bending and Shear." In American Society of Civil Engineers Proceedings, Vol. 87. Virginia: American Society of Civil Engineers.

[35] ANSYS, Inc. 2013. Structural Analysis Guide. Pennsylvania: ANSYS Inc.

[36] National Standard of the People's Republic of China. 2001. GB 50205: Code for Acceptance of Construction Quality of Steel Structures. Beijing: National Standard of the People's Republic of China.

[37] Zhang, L., and Tong, G. S. 2008. "Lateral Buckling of Web-Tapered I-Beams: A New Theory." Journal of Constructional Steel Research 64 (12): 1379-93.

[38] Huber, A. W., and Beedle, L. S. 1953. Residual Stress and the Compressive Strength of Steel. Technical report of Fritz Engineering Laboratory, Lehigh University, Bethlehem.

[39] Van der Neut, A. 1969. The Interaction of Local Buckling and Column Failure of Thin-Walled Compression Members. Berlin: Springer.

[40] Sridharan, S. 1977. "Elastic Postbuckling Behaviour and Crinkly Collapse of Plate Structures." Ph.D. thesis, University of Southampton. 